\title{
Slip history of the 2003 San Simeon earthquake constrained by combining 1-Hz GPS, strong motion, and teleseismic data
}

\author{
Chen Ji, ${ }^{1}$ Kristine M. Larson, ${ }^{2}$ Ying Tan, ${ }^{1}$ Kenneth W. Hudnut, ${ }^{3}$ and Kyuhong Choi ${ }^{2}$ \\ Received 6 May 2004; revised 4 June 2004; accepted 20 August 2004; published 15 September 2004.
}

[1] The slip history of the 2003 San Simeon earthquake is constrained by combining strong motion and teleseismic data, along with GPS static offsets and $1-\mathrm{Hz}$ GPS observations. Comparisons of a 1-Hz GPS time series and a co-located strong motion data are in very good agreement, demonstrating a new application of GPS. The inversion results for this event indicate that the rupture initiated at a depth of $8.5 \mathrm{~km}$ and propagated southeastwards with a speed $\sim 3.0 \mathrm{~km} / \mathrm{sec}$, with rake vectors forming a fan structure around the hypocenter. We obtained a peak slip of $2.8 \mathrm{~m}$ and total seismic moment of $6.2 \times 10^{18} \mathrm{Nm}$. We interpret the slip distribution as indicating that the hanging wall rotates relative to the footwall around the hypocenter, in a sense that appears consistent with the shape of the mapped fault trace. INDEX TERMS: 1242 Geodesy and Gravity: Seismic deformations (7205); 7212 Seismology: Earthquake ground motions and engineering; 8123 Tectonophysics: Dynamics, seismotectonics. Citation: Ji, C., K. M. Larson, Y. Tan, K. W. Hudnut, and K. Choi (2004), Slip history of the 2003 San Simeon earthquake constrained by combining 1-Hz GPS, strong motion, and teleseismic data, Geophys. Res. Lett., 31, L17608, doi:10.1029/2004GL020448.

\section{Introduction}

[2] Near-fault seismic data have been widely used to retrieve the slip history of large earthquakes since the pioneering studies of the 1979 Imperial Valley earthquake [e.g., Archuleta, 1984; Hartzell and Heaton, 1983; Olson and Apsel, 1982]. Such studies have provided quantitative measurements of earthquake rupture processes, but usually suffer from poor data coverage, limiting the resolution and reliability of the results. It has been suggested that combining geodetic and geological data with seismic data will improve data coverage, and provide more stable results than the inversions from individual data sets [Wald and Heaton, 1994]. However, seismic and geodetic data sample ground deformation at different time scales; whether or not they are compatible is sometimes an issue. For example, afterslip contamination has been reported in the recent study of the 1999 Chi-Chi earthquake [ $\mathrm{Ji}$ et al., 2003].

[3] Detailed measurement of 3D particle motion at a site, including the co-seismic dynamic and static, as well as early post-seismic motion, is typically recorded by

\footnotetext{
${ }^{1}$ Division of Geological and Planetary Sciences, California Institute of Technology, Pasadena, California, USA.

${ }^{2}$ Department of Aerospace Engineering Sciences, University of Colorado at Boulder, Boulder, Colorado, USA.

${ }^{3}$ U.S. Geological Survey, Pasadena, California, USA.
}

Copyright 2004 by the American Geophysical Union. 0094-8276/04/2004GL020448\$05.00 inertial sensors and can be achieved by complementary or stand-alone continuous GPS positioning (especially if sampled at $1 \mathrm{~Hz}$ or higher), as discussed by Hudnut [2000] and Nikolaidis et al. [2000, 2001] and first demonstrated by Larson et al. [2003]. While GPS sampling rates need to be increased still further, even $1-\mathrm{Hz}$ results have potential to provide a good supplement to the strong motion observations for finite-fault source studies. However, very few $1-\mathrm{Hz}$ GPS records have been made during earthquakes [e.g., Bock et al., 2004]. It is important, therefore, to compare 1-Hz GPS records with strong motion data recorded at co-located sites during large earthquakes. The 2003 San Simeon earthquake provides a unique dataset for such a comparison. In this paper, we first evaluate the quality of the 1-Hz GPS by direct comparison with a co-located strong motion instrument. We next combined $1-\mathrm{Hz}$ GPS time series with additional strong motion, teleseismic, and GPS static offset estimates in order to construct the slip history of this earthquake.

\section{2003 San Simeon Earthquake}

[4] The San Simeon earthquake was a $M_{w} 6.5$ blind thrust occurring on the Oceanic fault, $50 \mathrm{~km}$ west of the San Andreas fault [Hardebeck et al., 2004]. Using the seismic moment tensor solution [Hardebeck et al., 2004], aftershock relocation (courtesy of J. Hardebeck), and the trace of the Oceanic fault, we constructed a north-dipping fault plane that has a strike of $292^{\circ}$ and dip angle of $52^{\circ}$ to the northeast. In contrast with a more preliminary result, which used only teleseismic P waveforms [Hardebeck et al., 2004], in this study we used 8 strong motion observations, 5 1-Hz GPS observations, 14 GPS static displacements and 10 teleseismic $\mathrm{P}$ waveforms.

[5] The two closest CGS/CISN (California Geological Survey/California Integrated Seismic Network) strong motion records, CAMB and TEMP, had been highpass filtered at corner frequency about 0.1 and $0.12 \mathrm{~Hz}$ respectively, so we only utilized their velocity records in this study. In contrast, displacements of other CISN broadband strong motions and GSN (Global Seismic Network) teleseismic waveforms were used. Finally, we lowpass filtered all records to less than $1 \mathrm{~Hz}$ using a two-pass six-order Butterworth filter before conducting our inversions.

[6] The horizontal GPS static displacements were collected from nearby SCIGN (Southern California Integrated Geodetic Network) stations [Hudnut et al., 2002] which had been recently upgraded to track at $1-\mathrm{Hz}$ [Langbein and Bock, 2004]. The static offset of the closest station, Camp Roberts (CRBT), is $5.3 \mathrm{~cm}$ (Figure 1). The 1-Hz GPS position time series of five SCIGN stations were estimated using the methodology of Larson et al. [2003]. Their observational noise can be estimated by fitting the position 


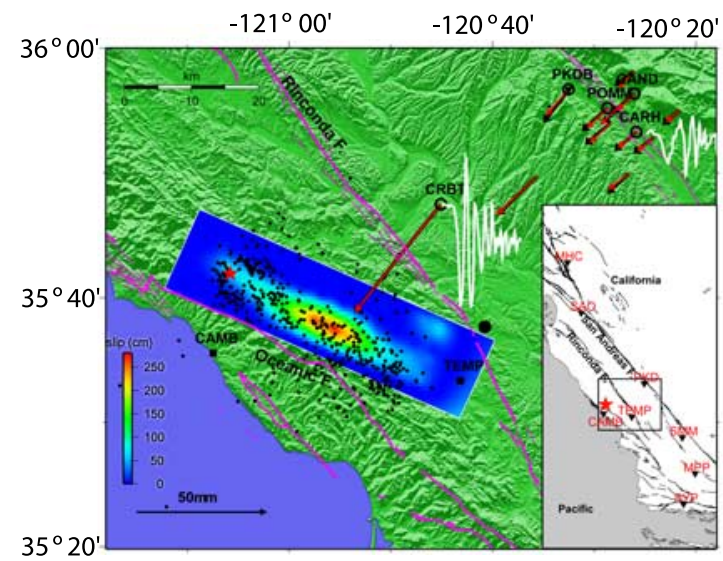

Figure 1. The 2003 San Simeon earthquake. A red star shows the epicenter in the inset location map along with strong motion stations used and nearby major faults. Surface projection of the derived slip distribution is shown in the main figure, against the aftershock distribution (black dots), with the color bar indicating the slip amplitude. Observed GPS horizontal static offsets (black arrows) are compared with synthetics (red arrows). Open circles indicate those stations whose 1-Hz GPS data were used to constrain this slip model. In particular, white lines show the east-component waveforms from GPS stations CRBT and CARH.

estimates before the earthquake initiation as a straight line. For station PKDB, the standard deviations of east, north, and vertical components are $0.3,0.7$, and $1.1 \mathrm{~cm}$ respectively. The relative size of the east and north component precision is caused by the difference in how the satellites are distributed in the sky at the time of the San Simeon earthquake (electronic supplement ${ }^{1}$, Figure S1). The station Parkfield has both a high sample-rate GPS sensor (PKDB) and a lowgain strong motion instrument (PKD). This co-location provides a good opportunity to directly evaluate the quality of these new data. We used a baseline correction method suggested by $Z h u$ [2003] to convert acceleration records into displacements, and compared them with the 1-Hz GPS data in Figure 2. To avoid the bias caused by coarser GPS sampling, both data sets have been lowpass filtered using a two-pass six-order Butterworth filter with a corner frequency of $0.5 \mathrm{~Hz}$. To explore the frequency dependence of observational noise, we also present a comparison of ground velocity derived from GPS and seismic records.

[7] Results show that the east component matches the seismic observations very well (Figure 2). The mismatch becomes larger for the north component and even comparable to seismic signal itself for the vertical component, which is partially due to the fact that the vertical seismic signal is only about half the size of the horizontal components. While the integrated strong motion also includes errors caused by instrument noise and the double-integration process [Boore et al., 2002], this result is consistent with the aforementioned standard deviations of 1-Hz GPS. Interestingly, differentials of the GPS time series visually match the ground velocities better than do the displacements. This is consistent with studies that find GPS errors to have more low than high

${ }^{1}$ Auxiliary material is available at ftp://ftp.agu.org/apend/gl/ 2004GL020448. frequency content [Bock et al., 2004; Langbein and Bock, 2004]. If this is the case, we may be able to easily improve upon the high-frequency band limits of continuous GPS by simply increasing the sampling rate. Since the displacement amplitudes at other GPS sites are comparable to, or even larger than, those at PKDB, we concluded that the horizontal 1-Hz GPS data can be used to constrain the fault rupture of the 2003 San Simeon earthquake. Depending on the size and mechanism of the earthquake and location of the GPS receivers, $1-\mathrm{Hz}$ GPS vertical records can also be used to constrain fault slip [Larson et al., 2004].

[8] We used a recently developed finite-fault inverse method that carries out the waveform inversion in the wavelet domain, and then applies a simulated annealing method to search for global optimal solutions [Ji et al., 2002]. During this study, the fault plane was further divided into $3 \mathrm{~km}$ by $2 \mathrm{~km}$ subfaults. For each subfault, we simultaneously inverted for subfault slip, rake angle, rupture initiation time, and shape of an asymmetric time function. During the inversion, we applied moment minimization and spatial Laplacian smoothing constraints. The weights of normalized constraint functions [Ji et al., 2002] were chosen after several trial inversions to explore the trade off between the fits to the data and values of constraint functions. We let the slip amplitude vary from 0 to $3 \mathrm{~m}$ and rake angle change from $60^{\circ}$ to $120^{\circ}$. We allowed the starting time and end time [ $\mathrm{Ji}$ et al., 2003] to range from 0.2 to $2 \mathrm{sec}$. The total rise time of each subfault is therefore limited to 0.4 to $4 \mathrm{sec}$. For the observations recorded at stations less than $100 \mathrm{~km}$ from the hypocenter, we chose a velocity structure suggested by Walter and Mooney [1982] to generate both static and seismic Green's functions [Xie and Yao, 1989; Zhu, 2003]. The Southern California Crust model (Socal [Dreger and Helmberger, 1993]) was used to generate the waveforms of distant stations. Since there is no surface rupture [Hardebeck et al., 2004], the slip of near-surface subfaults was held fixed at zero.

\section{Inversion Results}

[9] The inverted slip history is shown in the top panel of Figure 3. Slip initiated at a depth of $8.5 \mathrm{~km}$, and ruptured

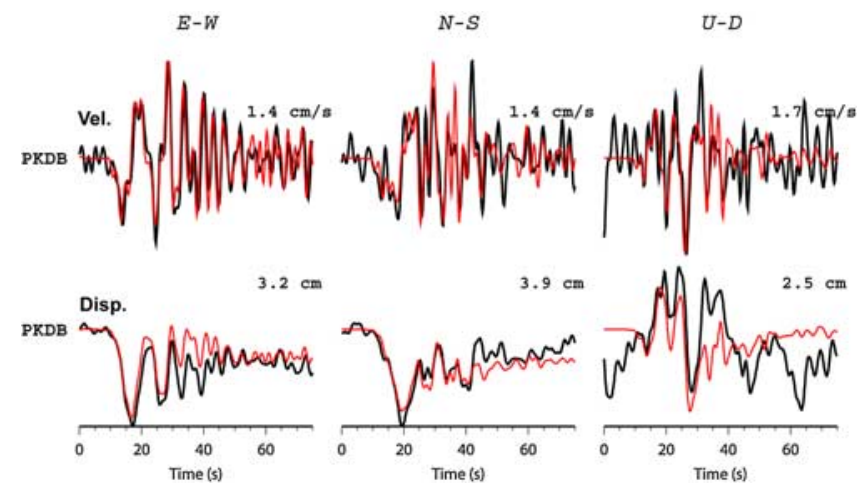

Figure 2. Comparison of 1-Hz GPS data (black lines) and both single and double-integrated strong motion (red lines) at station PKD. To obtain velocity traces, the GPS time series were differentiated. All traces are aligned by the origin time, as given by CISN. The peak amplitude of each trace is indicated. 


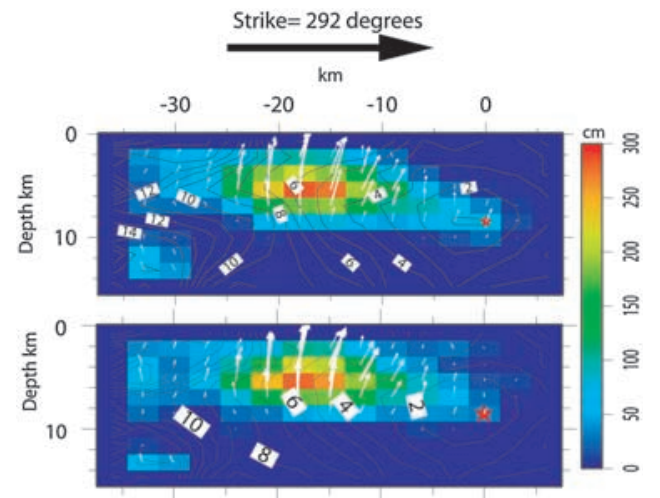

Figure 3. Slip distribution of the 2003 San Simeon earthquake. The top panel shows the slip distribution using all data. The bottom shows the result if the strong motion station PKD is removed. The red star in each panel shows the hypocenter's location. The color indicates the slip amplitude and white arrows show the slip directions. The contours show the rupture initiation time in sec.

southeastwards with a rupture velocity of $3.0 \mathrm{~km} / \mathrm{s}$. The width of the slip patch (along the downdip direction) also grew as the rupture propagated, finally forming a fanshaped asperity centering upon the hypocenter. Most slip occurred from 10 to $25 \mathrm{~km}$ southeast of the hypocenter, and in a depth range between 2 and $8 \mathrm{~km}$. The maximum slip was $2.8 \mathrm{~m}$, and the total seismic moment was $6.2 \times$ $10^{18} \mathrm{Nm}$, consistent with other results [e.g., Dreger et al., 2004]. We tested the robustness of the results by slightly changing the strike and dip angles of the a priori fault plane. We found that the slip pattern from 0 to $25 \mathrm{~km}$ is very robust, but that the small amount of slip around $30 \mathrm{~km}$ southeast of the epicenter is not well-resolved, and is very sensitive to assumed fault strike. We also noticed that the distant strong motions and the teleseismic data were not very sensitive to the spatial variation of rake angle (Figure 3), but it improves the waveform fits of closer seismic and 1-Hz GPS records, particularly for the stations CAMB and TEMP.

[10] Figure 4 shows the comparison of 1-Hz GPS time series and synthetic seismograms. The waveform comparisons of other datasets are provided in electronic supplement (Figures S2-S5). The model explains the dominant portions of the records very well. The waveforms of the four stations along the San Andreas fault are similar, but still show the fingerprints of fault finiteness. For instance, the north component of the station CARH contains a much narrower pulse than that of station PKD. Because the former station is located $15 \mathrm{~km}$ southeast of the latter one (Figure 4), this waveform compression is presumably caused by the southeast-directed fault rupture, which is well reproduced by synthetic seismograms. The mismatches are also significant. The synthetic seismograms failed to explain the highfrequency oscillations showed in the east component of CARH and vertical component of CRBT. These are likely due to local site effects that we didn't include in our modeling. The model also could not explain the long period northward motions showed in station PKDB and CARH (40 sec after the $\mathrm{P}$ arrivals). This signal is not apparent in other stations and could be observational noise [Langbein and Bock, 2004].
[11] Since it is the combination of strong motion PKD and $1-\mathrm{Hz}$ GPS stations that provides the azimuth coverage northeast of the fault plane, we tested whether the constraint could be entirely made by $1-\mathrm{Hz}$ GPS. The lower panel of Figure 3 shows the inverted result without strong motion station PKD. It is very close to our preferred results, as expected. The vertical component of PKD, however, still provides a unique constraint upon the fault rupture parameters we estimated. For example, this is probably why the asperity's boundary becomes less sharp in this model.

\section{Discussion}

[12] This earthquake ruptured in a fan-shaped pattern around the hypocenter, with the slip vectors seeming to draw an arc relative to the hypocenter (Figure 3). This result suggests that the hanging wall may have co-seismically rotated clockwise relative to the footwall, with the epicenter as the center. Interestingly, the Oceanic fault changes direction where the large slip initiated in this event (Figure 1). We tested the possibility of whether this event occurred on a bent fault plane by performing inversions using multiple planes to match such a curved fault. We rejected this model, however, because it required 30\% more seismic moment to match the GPS static offsets, and also decreased the quality of waveform fits at TEMP. Even though the explanation of why the fault trace changes strike may not be unique, if the rotation of the hanging wall is representative of past earthquakes on this fault, events will disturb the fault planes and the hanging and footwall block
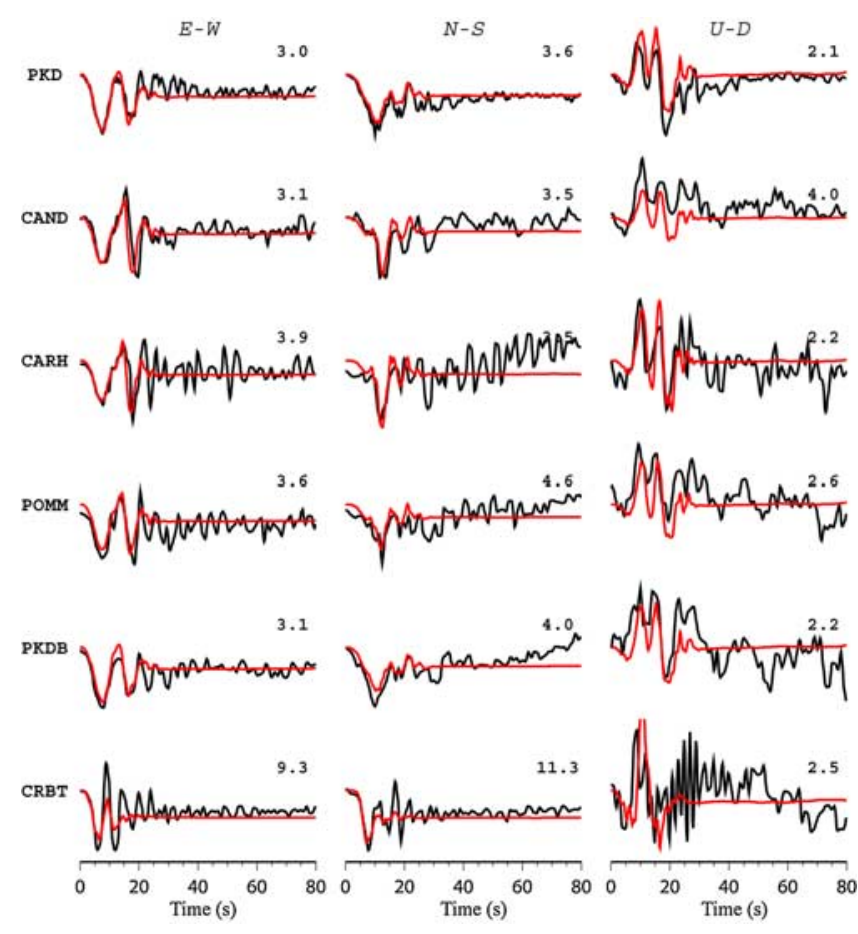

Figure 4. Comparison of data (black lines) and synthetic seismograms (red lines). Both data and synthetics are aligned by the $\mathrm{P}$ times. The first trace is the integrated strong motion. The rest are $1-\mathrm{Hz}$ GPS data. The number above each trace indicates the peak amplitude of this record in $\mathrm{cm}$. 
in the same way each time, resulting in net rotation over the long term. The position of the main asperity is located where the Oceanic fault merges with the Nacimiento fault (E. Hauksson et al., Imaging the source region of the 2003 San Simeon earthquake within the weak Franciscan subduction complex, central California, submitted to Geophysical Research Letters, 2004). The complex interaction of these two faults could give rise to heterogeneous loading, and hence variable and large slip.

[13] While the performance of $1-\mathrm{Hz}$ GPS data could be greatly improved as the number of satellites increases (by combining GPS, GLONASS, and satellites from the planned European constellation Galileo), our present results demonstrate that the current precision of horizontal components is excellent for measuring the near-fault motions of large earthquakes, which are usually up to tens of centimeters or even meters. For such large motions, 1-Hz GPS has several advantages, as compared with strong motion data. First, 1-Hz GPS has very accurate timing information. In contrast, most of the triggered strong motion stations still have timing problems. For example, we found that there was a 20-second clock error associated with station TEMP. Second, near-field horizontal strong motion records are usually contaminated by co-seismic ground tilts and analogto-digital conversion [e.g., Boore, 2003], which makes it difficult to accurately retrieve ground displacements using the double-integration process. This appears not to be a problem for $1-\mathrm{Hz}$ GPS. Since $0.5 \mathrm{~Hz}$ is close to the limitation that we could reasonably model using synthetic seismogram algorithms, the $1-\mathrm{Hz}$ GPS systems provide an ideal measurement method for finite-fault source studies, and a much-needed supplement to existing observations. Not only increased rate of GPS recordings, but co-location of high sample-rate GPS receivers and strong motion instruments would add greatly to near-field spatial and frequency coverage for source models of future earthquakes. We recommend, therefore, that efforts in these directions be increased, not only for real-time telemetered sites in support of emergency response applications, but also in the interest of improving the future data sets that will be needed for progress in fundamental research on earthquake source physics.

[14] Acknowledgments. We thank Lupei Zhu for deconvolution scripts and Jeanne Hardebeck for fault plane information. Discussions with Egill Hauksson were very constructive. Reviews by Don Helmberger, John Langbein, Nancy King, and an anonymous reviewer improved the manuscript. Seismic data were provided by CISN and IRIS DMC. We acknowledge SCIGN and its funders (W. M. Keck Foundation, NASA, NSF, USGS, SCEC) as the source of the GPS data. We especially thank Yehuda Bock and John Langbein for their efforts in updating the Parkfield GPS Array to record at 1-Hz. UCSD, SCIGN, USGS, and UCB all contributed to the development of the array. Assistance with GPS data, archiving, and analysis software was provided by SOPAC, UNAVCO, and JPL-Caltech. This paper is supported by USGS grant \#04HQGR0048, NSF grant \#EAR-0337206, and the Gordon and Betty Moore Foundation. This is Caltech Seismological Laboratory contribution 9077 and Caltech Tectonic Observatory contribution \#6.

\section{References}

Archuleta, R. J. (1984), A faulting model for the 1979 Imperial Valley earthquake, J. Geophys. Res., 89(B6), 4559-4585.

Bock, Y., L. Prawirodirdjo, and T. I. Melbourne (2004), Detection of arbitrarily large dynamic ground motions with a dense high-rate GPS network, Geophys. Res. Lett., 31, L06604, doi:10.1029/2003GL019150.
Boore, D. M. (2003), Analog-to-digital conversion as a source of drifts in displacements derived from digital recordings of ground acceleration, Bull. Seismol. Soc. Am., 93, 2017-2024.

Boore, D. M., C. D. Stephens, and W. B. Joyner (2002), Comments on baseline correction of digital strong-motion data: Examples from the 1999 Hector Mine, California, earthquake, Bull. Seismol. Soc. Am., 92, $1543-1560$.

Dreger, D. S., and D. V. Helmberger (1993), Determination of source parameters at regional distances with 3-component sparse network data, J. Geophys. Res., 98(B5), 8107-8125.

Dreger, D., P. Lombard, J. Boatwright, D. Wald, and L. Gee (2004), Finite source models of the December 22, 2003 San Simeon earthquake and applications to ShakeMap, paper presented at 2004 SSA Annual Meeting, Seismol. Soc. of Am., Palm Springs, Calif.

Hardebeck, J. L., et al. (2004), Preliminary report on the 22 December 2003, M6.5 San Simeon, California earthquake, Seismol. Res. Lett., $75(2), 155-172$

Hartzell, S. H., and T. H. Heaton (1983), Inversion of strong ground motion and teleseismic waveform data for the fault rupture history of the 1979 Imperial Valley, California, earthquake, Bull. Seismol. Soc. Am., 73, $1553-1583$

Hudnut, K. W. (2000), GPS in earthquake monitoring networks (abstract), Seismol. Res. Lett., 71(1), 261.

Hudnut, K. W., Y. Bock, J. E. Galetzka, F. H. Webb, and W. H. Young (2002), The Southern California Integrated GPS Network (SCIGN), in Seismotectonics in Convergent Plate Boundary, edited by Y. Fujinawa and A. Yoshida, pp. 167-189, Terra Sci., Tokyo.

Ji, C., D. J. Wald, and D. V. Helmberger (2002), Source description of the 1999 Hector Mine, California, earthquake, part I: Wavelet domain inversion theory and resolution analysis, Bull. Seismol. Soc. Am., 92, $1192-$ 1207.

Ji, C., D. V. Helmberger, D. J. Wald, and K. F. Ma (2003), Slip history and dynamic implications of the 1999 Chi-Chi, Taiwan, earthquake, J. Geophys. Res., 108(B9), 2412, doi:10.1029/2002JB001764.

Langbein, J., and Y. Bock (2004), High-rate real-time GPS network at Parkfield: Utility for detecting fault slip and seismic displacements, Geophys. Res. Lett., 31, L15S20, doi:10.1029/2003GL019408.

Larson, K. M., P. Bodin, and J. Gomberg (2003), Using 1-Hz GPS data to measure deformations caused by the Denali fault earthquake, Science, 300(5624), 1421-1424.

Larson, K. M., S. Miyazaki, K. Choi, K. Koketsu, K. Hikima, A. Yamagiwa, J. Haase, P. Bodin, J. Gomberg, and J. Clinton (2004), Analysis of highrate GPS data from the Tokachi-Oki (Hokkaido) earthquake, paper presented at 2004 IRIS Annual Workshop, Inc. Res. Inst. for Seismol., Tucson, Ariz., 10-12 June.

Nikolaidis, R. M., Y. Bock, D. C. Agnew, P. J. de Jonge, and M. Van Domselaar (2000), Near-real-time GPS observation of permanent coseismic displacement and strong motion from the $\mathrm{M}_{\mathrm{w}}$ 7.1 Hector Mine earthquake (abstract), Seismol. Res. Lett., 71(1), 261.

Nikolaidis, R. M., Y. Bock, P. J. de Jonge, P. Shearer, D. C. Agnew, and M. Van Domselaar (2001), Seismic wave observations with the Global Positioning System, J. Geophys. Res., 106(B10), 21,897-21,916.

Olson, A. H., and R. J. Apsel (1982), Finite faults and inverse-theory with applications to the 1979 Imperial Valley earthquake, Bull. Seismol. Soc. Am., 72, 1969-2001.

Wald, D. J., and T. H. Heaton (1994), Spatial and temporal distribution of slip for the 1992 Landers, California, earthquake, Bull. Seismol. Soc. Am., $84,668-691$

Walter, A. W., and W. D. Mooney (1982), Crustal structure of the Diablo and Gabilan ranges, central California: A reinterpretation of existing data, Bull. Seismol. Soc. Am., 72, 1567-1590.

Xie, X., and Z. X. Yao (1989), A generalized reflection-transimission coefficient matrix method to calculate static displacement field of a dislocation source in a stratified half-space, Chin. J. Geophys., 32, 191-205.

Zhu, L. P. (2003), Recovering permanent displacements from seismic records of the June 9, 1994 Bolivia deep earthquake, Geophys. Res. Let., 30(14), 1740, doi:10.1029/2003GL017302.

K. Choi and K. M. Larson, Department of Aerospace Engineering Sciences, University of Colorado at Boulder, Boulder, CO, USA.

K. W. Hudnut, U.S. Geological Survey, Pasadena, CA, USA.

C. Ji and Y. Tan, Division of Geological and Planetary Sciences, California Institute of Technology, Pasadena, CA 91125, USA. (jichen@gps.caltech.edu) 